\title{
Author Correction: Detection of renal cell carcinoma using plasma and urine cell-free DNA methylomes
}

Pier Vitale Nuzzo @ , Jacob E. Berchuck @i , Keegan Korthauer, Sandor Spisak, Amin H. Nassar (1D, Sarah Abou Alaiwi, Ankur Chakravarthy, Shu Yi Shen (1D, Ziad Bakouny (D), Francesco Boccardo, John Steinharter, Gabrielle Bouchard, Catherine R. Curran, Wenting Pan, Sylvan C. Baca, Ji-Heui Seo, Gwo-Shu Mary Lee, M. Dror Michaelson, Steven L. Chang, Sushrut S. Waikar, Guru Sonpavde, Rafael A. Irizarry, Mark Pomerantz, Daniel D. De Carvalho (D), Toni K. Choueiri (D) and Matthew L. Freedman (D)

Correction to: Nature Medicine https://doi.org/10.1038/s41591-020-0933-1, published online 22 June 2020.

In the version of this article initially published, some statements of support were missing from the Acknowledgements section. The correct ending for that section is as follows: "T.K.C. is supported in part by the Dana-Farber/Harvard Cancer Center Kidney SPORE and Program, the Kohlberg Chair at Harvard Medical School and the Trust Family, Michael Brigham, and Loker Pinard Funds for Kidney Cancer Research at DFCI. Funding in part by Department of Defense Award W81XWH1910553/Development and Testing of Circulating-Free Methylation DNA as a Prognostic Biomarker for Recurrent Kidney Cancer (PI: T.K.C.)." The error has been corrected in the HTML and PDF versions of the article.

Published online: 7 September 2020

https://doi.org/10.1038/s41591-020-1078-y

๑ The Author(s), under exclusive licence to Springer Nature America, Inc. 2020

\section{Author Correction: A dynamic COVID-19 immune signature includes associations with poor prognosis}

Adam G. Laing, Anna Lorenc (D), Irene del Molino del Barrio, Abhishek Das (D), Matthew Fish (D), Leticia Monin (D), Miguel Muñoz-Ruiz, Duncan R. McKenzie D , Thomas S. Hayday, Isaac Francos-Quijorna, Shraddha Kamdar, Magdalene Joseph, Daniel Davies, Richard Davis, Aislinn Jennings (D), Iva Zlatareva, Pierre Vantourout (D), Yin Wu (D), Vasiliki Sofra, Florencia Cano D, Maria Greco, Efstathios Theodoridis, Joshua Freedman, Sarah Gee (iD, Julie Nuo En Chan, Sarah Ryan, Eva Bugallo-Blanco (D), Pärt Peterson (D), Kai Kisand ID, Liis Haljasmägi, Loubna Chadli, Philippe Moingeon (ID, Lauren Martinez (D), Blair Merrick (D), Karen Bisnauthsing, Kate Brooks, Mohammad A. A. Ibrahim (D), Jeremy Mason (D), Federico Lopez Gomez D, Kola Babalola, Sultan Abdul-Jawad, John Cason, Christine Mant, Jeffrey Seow, Carl Graham, Katie J. Doores, Francesca Di Rosa, Jonathan Edgeworth, Manu Shankar-Hari (D) and Adrian C. Hayday (D)

Correction to: Nature Medicine https://doi.org/10.1038/s41591-020-1038-6, published online 17 August 2020.

In the version of this article initially published online, a statement of support was missing from the Acknowledgements section. The correct ending of the fourth sentence of that section is as follows: “...; and Royal Society Grant IES \R3\170319 (A.C.H. and F.D.R.)." The error has been corrected in the print, HTML and PDF versions of the article.

Published online: 9 September 2020

https://doi.org/10.1038/s41591-020-1079-x

(c) The Author(s), under exclusive licence to Springer Nature America, Inc. 2020 